УДК 66-2

\title{
УПРАВЛЕНИЕ ЗОНОЙ СХЛОПЫВАНИЯ КАВИТАЦИОННЫХ ПУЗЫРЬКОВ В ЗАДВИЖКЕ СТАБИЛИЗАТОРОМ
}

\author{
Д. В. Логинов, С. А. Сухов, А. В. Фоминых, И. Р. Чиняев
}

Применение запорных клиновых задвижек для регулирования потока жидкости (не по назначению) приводит к разрушению деталей затвора. В статье изложены устройство и работа шиберной запорно-регулирующей задвижки со стабилизатором, позволяющим управлять расположением зоны схлопывания кавитационных пузырьков. Стабилизатор поджат к торцевой поверхности шибера пружиной. Поджатие обеспечивает совместное их перемещение вплоть до упора плеч стабилизатора в корпус. Нижняя торцевая радиусная поверхность шибера и ответная поверхность стабилизатора снабжены рядом канавок. Канавки делят поток жидкости на отдельные струи и направляют их в выходной патрубок, что уменьшает эрозионный и кавитационный износ деталей затвора. Расчёты в программе ANSYS показали, что при перепаде давления на клиновой задвижке 0,8 МПа в зоне за шибером вакуум приближается к давлению насыщенных паров. Для предлагаемой шиберной запорно-регулирующей задвижки со стабилизатором давление насыщенных паров может быть достигнуто на входе в канавки между шибером и стабилизатором и на выходе из них при перепаде давления 0,45 МПа. Можно сделать вывод, что в этих зонах начинается процесс кавитации, но схлопывание пузырьков в серийной задвижке происходит сразу за клином, а в предлагаемой задвижке в выходном патрубке в районе фрланцев, и это особенно важно в начальной стадии открытия. Ускоренные испытания предлагаемой задвижки проведены в производственных условиях при перепадах давлении 17 МПа. После восемнадцати месяцев эксплуатации герметичность и фрункция регулирования задвижки MKTR сохранились. Запорная клиновая задвижка в таких условиях эксплуатации теряет герметичность через три месяца.

Ключевые слова: задвижка, затвор, седло, шибер, стабилизатор, жидкость, кавитация, разрушение, давление, эпюры скоростей, расчёты в программе ANSYS, производственные испытания.

\section{ВВЕДЕНИЕ}

В клиновых задвижках под шибером и после него возникает сильная турбулизация потока, завихрения жидкости, что является причиной разрушения деталей затвора (рисунок 1).
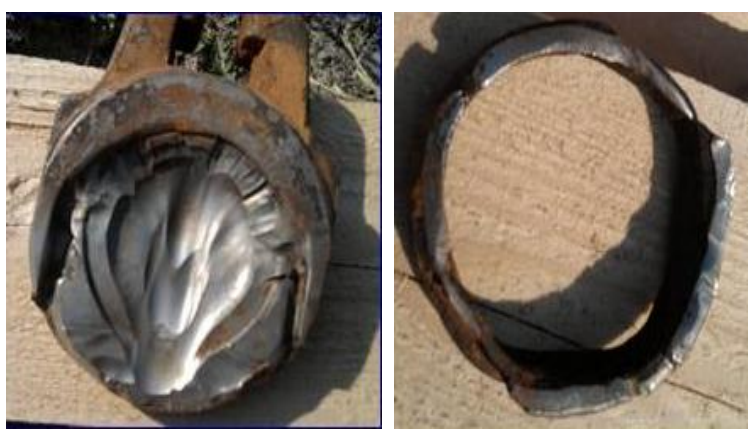

Рисунок 1 - Тыльная сторона клина и седло клиновой задвижки после шести месяцев эксплуатации в режиме регулирования
Большие скорости жидкости и кавитация за клином являются причиной износа и разрушений (рисунок 2).

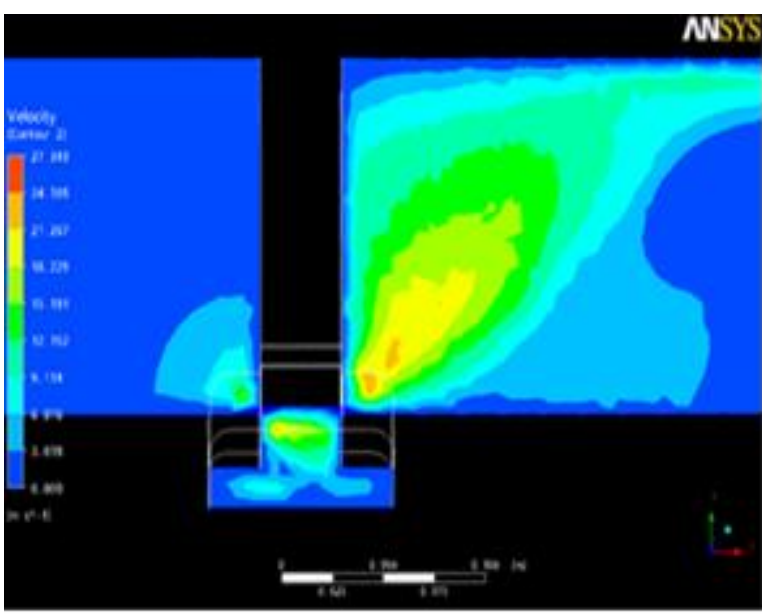

Рисунок 2 - Эпюры скоростей потока воды в серийной задвижке 
Поэтому применение запорных клиновых задвижек для регулирования потока жидкости (не по назначению) приводит к разрушению деталей затвора [1-12].

\section{МЕТОДИКА}

Нами разработана запорно-регулирующая задвижка со стабилизатором, расположенным под шибером (патент на изобретение № 2464470 и на полезную модель № 77657) (рисунок 3).

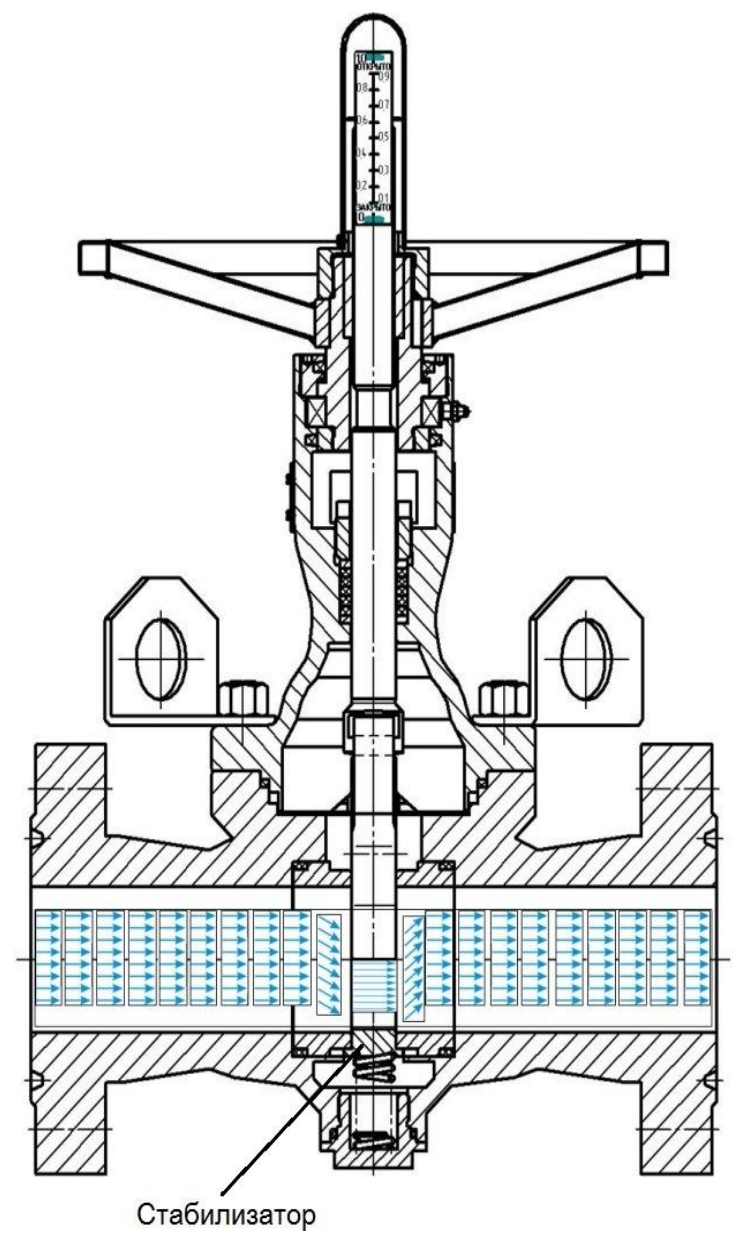

Рисунок 3 - Задвижка запорно-регулирующая MKTR

Стабилизатор поджат к торцевой поверхности шибера пружиной. Поджатие обеспечивает совместное их перемещение вплоть до упора плеч стабилизатора в корпус. При этом стабилизатор занимает пространство под шибером и закрывает нижнюю часть уплотнительных полей сёдел от воздействия потока жидкости. Нижняя торцевая радиусная поверхность шибера и ответная поверхность стабилизатора снабжены рядом канавок (рисунок 4).

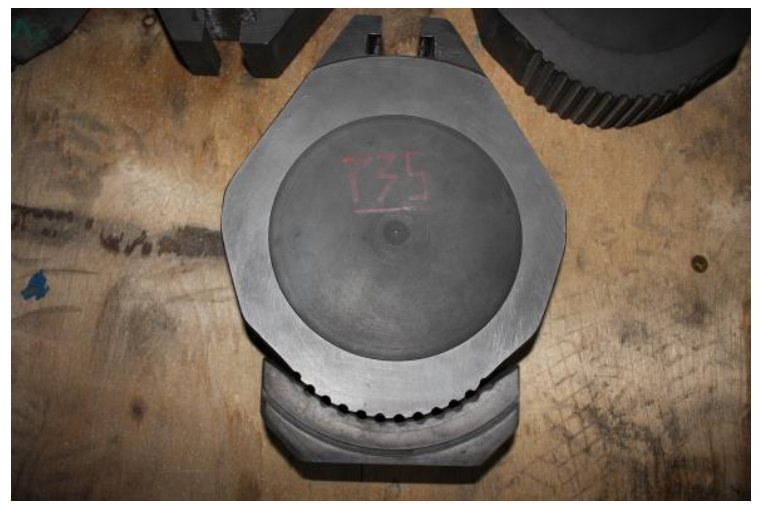

Рисунок 4 - Шибер в сборе со стабилизатором

Канавки делят поток жидкости на отдельные струи и направляют их в выходной патрубок, что уменьшает эрозионный и кавитационный износ деталей затвора. Зона схлопывания кавитационных пузырьков в выходном патрубке (рисунок 5).

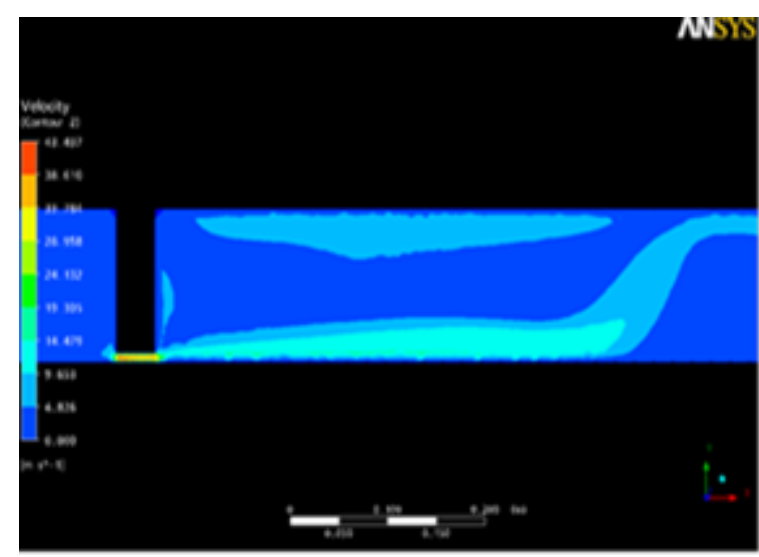

Рисунок 5 - Эпюры скоростей при диаметре отверстий 7 мм

Из рисунка видно, что выйдя из канавок, как из круглых насадок, струи текут вдоль нижней стенки корпуса и выходного патрубка задвижки. Увеличение сечения (высоты) канавок приводит к увеличению ширины уплотнительных полей и хода шибера. При рациональном диаметре отверстий, образованных канавками, необходимо обеспечить максимальный диапазон тонкого регулирования расхода, что достигается увеличением количества отверстий. Увеличение количества отверстий приводит к уменьшению толщины стенки между ними. Из условий износостойкости толщина стенки не может быть меньше диаметра отверстий.

Стабилизатор уменьшает турбулизацию потока жидкости за шибером. Меняя кон- 
струкцию стабилизатора, можно управлять местом расположения зоны образования и местом расположения зоны схлопывания кавитационных пузырьков. При достижении абсолютного давления в отдельных участках потока давления насыщенных паров возникает кавитация. В расчётах принимали температуру воды 20 градусов, при этом давление насыщенных паров равно 2,3 кПа, то есть близко к нулю. Расчёты в программе ANSYS показали, что при перепаде давления на клиновой задвижке 0,8 МПа в зоне за шибером вакуум приближается к давлению насыщенных паров.

Для предлагаемой шиберной запорнорегулирующей задвижки со стабилизатором давление насыщенных паров может быть достигнуто на входе в канавки между шибером и стабилизатором и на выходе из них при перепаде давления 0,45 МПа. Можно сделать вывод, что в этих зонах начинается процесс кавитации, но схлопывание пузырьков в серийной задвижке происходит сразу за клином, а в предлагаемой задвижке - в выходном патрубке в районе фланцев, и это особенно важно в начальной стадии открытия.

Ускоренные испытания предлагаемой задвижки проведены в производственных условиях при перепадах давлении $17 \mathrm{MПа.}$ После восемнадцати месяцев эксплуатации герметичность и функция регулирования задвижки MKTR сохранились (рисунок 6). Запорная клиновая задвижка в таких условиях эксплуатации теряет герметичность через три месяца, а через 6 месяцев выглядит как на рисунке 1.
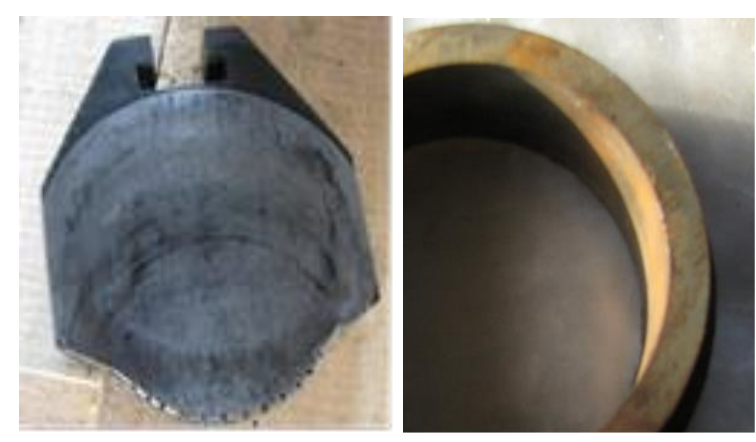

Рисунок 6 - Шибер и седло запорно-регулирующей задвижки MKTR после восемнадцати месяцев эксплуатации

Из анализа состояния задвижек после производственных испытаний определены площади их проходных сечений в зависимости от хода шибера. На основании этих данных рассчитаны зависимости расхода через задвижки от хода регулирующего элемента (рисунок 7).

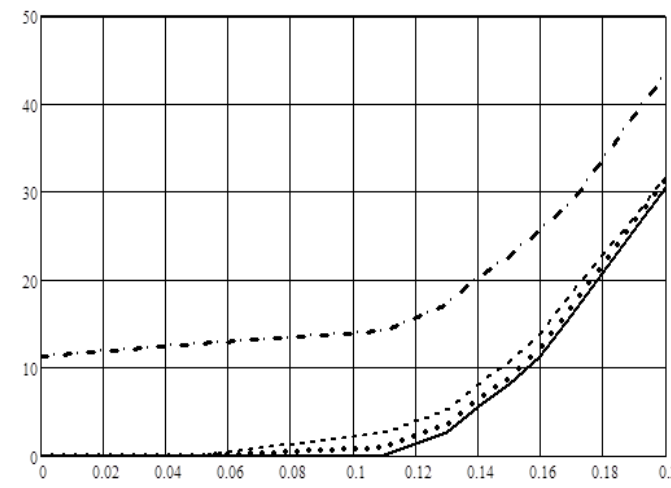

1 - запорно-регулирующая задвижка

новая; 2 - запорно-регулирующая задвижка после 18 месяцев эксплуатации;

3 - запорная клиновая задвижка новая;

4 - запорная клиновая задвижка после 6 месяцев эксплуатации

Рисунок 7 - Зависимости расхода через задвижки от хода регулирующего элемента при перепаде давления 100 кПа

У новой запорно-регулирующей задвижки дросселирование воды начинается при 0,1 хода шибера, кривая 1. Через 18 месяцев работы - при 0,05 хода шибера, кривая 2. У новой запорной клиновой задвижки дросселирование воды начинается при 0,08 хода шибера, кривая 3. После 6 месяцев работы через клиновую задвижку при клине в нижнем положении проходит воды более 10 м3/ч, кривая 4.

\section{выводы}

1. Проектные и эксплуатирующие трубопроводную арматуру организации часто устанавливают запорные задвижки в режиме регулирования, что приводит к появлению кавитации, интенсивному износу, и арматура быстро выходит из строя.

2. Разработаны шиберные запорнорегулирующие задвижки со стабилизатором, позволяющим управлять расположением зоны схлопывания кавитационных пузырьков.

3. Проведены ускоренные испытания предлагаемой задвижки в производственных условиях при перепадах давлении $17 \mathrm{MПа.}$ После восемнадцати месяцев эксплуатации герметичность и функция регулирования предлагаемой задвижки сохранились. Запорная клиновая задвижка в таких условиях эксплуатации теряет герметичность через три месяца.

4. Предлагаемые запорно-регулирующие ПОЛЗУНОВСКИЙ ВЕСТНИК № 42018 


\section{УПРАВЛЕНИЕ ЗОНОЙ СХЛОПЫВАНИЯ КАВИТАЦИОННЫХ ПУЗЫРЬКОВ В ЗАДВИЖКЕ СТАБИЛИЗАТОРОМ}

задвижки диаметром от 80 до 200 мм, выпускаемые ООО НПФ «МКТ-АСДМ» в городе Курган, нашли широкое применение в нефтегазовой отрасли и могут найти широкое применение в системах тепло и водоснабжения, мелиорации, системах гидромеханизации сельскохозяйственных процессов и везде, где необходимо обеспечить высокую точность процесса регулирования потоков жидкости в течение продолжительного времени.

\section{СПИСОК ЛИТЕРАТУРЫ}

1. Бирюков, А. В. Обоснование и разработка многоблочной установки очистки природного газа от твердых частиц / Бирюков А. В., Усачев А. П., Шурайц А. Л. // Нефртегазовое дело. - 2012. № 4. - С. 437-448.

2. Байкова, Л. Р. Алгоритм расчета показателей энергоэффек-тивности оборудования систем поддержания пластового давления / Байкова Л. Р., Гаррис Н. А. // Нефтегазовое дело. 2018. - T. 16. - № 2. - С. 61-66.

3. Найгерт, К. В. Технологии управления расходными характеристиками потока посредством изменения реологических свойств рабочих сред / Найгерт К. В., Редников С. Н. // Вестник ЮУрГУ, серия «Машиностроение» Том 16, № 2 (2016) - С. 52-60.

4. Регулирование расхода на водозаборе в системе первого подъёма воды / Сухов С. А. Чиняев И. Р., Фоминых А. В. [и др.] // АПК России. 2014. - T. 70 - С. 136-140.

5. Гуревич, Д. Ф. Конструирование и расчет трубопроводной арматуры / Гуревич Д. Ф. М.:Машиностроение, 1968. - 888 с.

6. Идельчик, И. Е. Справочник по гидравлическим сопротивлениям / Идельчик И. Е. -М.: Машиностроение, 1975. - 559 с.

7. Сейнов, С. В. Трубопроводная арматура. Исследования. Производство. Ремонт / Сейнов С. В. - М.: Машиностроение, 2002. - 390 с.

8. ГОСТ Р 55508-2013 Арматура трубопроводная. Методика эксперимен-тального определения гидравлических и кавитационных характеристик.

9. Сухов, С. А. Запорно-регулирующее устройство с проходным отверстием в шибере // Материалы международной научно-практической конференции Современное состояние и перспективы развития агропромышленного комплекса, Курган: Изд-во Курганской ГСХА, 2016. - C. $492-496$.

10. Шиберное запорно-регулирующее устройство / Сухов С. А., Чиняев И. Р., Фоминых А. $\mathrm{B}$.

[и др.] // Трубопроводная арматура и оборудование. - 2017. - № 5. - С. 36 - 39.

11. Логинов, Д. В. Обзор методов упрочнения трущихся поверхностей / Логинов Д. В., Фоминых А. В. // Техническое обеспечение технологий производства сельскохозяйственной продукции: материалы Всероссийской научно- практической конференции. - 2017. - Курган: Издво Курганской ГСХА. - С. 36-41.

12. Гидравлические и кавитационные характеристики регулирующих клапанов в диапазоне давлений до 3,0 МПа / Котельников Л. В., Пошивалов Е. А., Чиняев И. Р., Шанаурин А. Л., Фоминых А. В. // Трубопроводная арматура. 2017. - № 2 - C. 54-55.

13. Шпаков, О. Н. Трубопроводная арматура. Справочник специалиста // СПб.- М.: Информационно-издательский центр "КХТ", 2007. $-463 \mathrm{c}$.

14. Эйсмонт, В. П. Регуляторы / Эйсмонт В. П. - СПб.: Издательство ООО «Дитон», 2012. $-326 \mathrm{c}$.

15. Чиняев, И. Р. Определение гидравлических характеристик запорнорегулирующих задвижек / Чиняев И. Р., Фоминых А. В., Овчинников В. М. // Аграрный вестник Урала. - Екатеринбург: Изд-во Уральской ГСХА, 2013. № C. 23-26.

16. Чиняев, И. Р. Пример расчета прохождения среды через запорно-регулирующую задвижку / Чиняев И. Р., Шанаурин А. Л., Фоминых А. В. // Зауральский научный вестник. Вып.2(2012). - Курган: Институт развития образования и социальных технологий, КГУ, 2012. - С. 20-21.

17. Шиберное запорно-регулирующее устройство / Сухов С.А., Чиняев И.Р., Фоминых A.B.

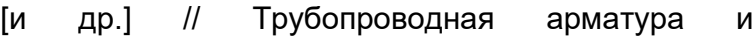
оборудование. - 2017. - № 5. - С. 36 - 39.

18. Ездина, А. А. Регулирующее устройство с использованием скручивания потока проводимой среды / Ездина А. А., Пономарева О. А., Фоминых А. В. // Научное обеспечение реализации государственных программ АПК и сельских территорий, 2017. - С. 393-396.

19. Повышение надёжности и эфффективности работы шиберной запорно-регулирующей задвижки / Сухов С.А., Чиняев И.Р., Фоминых А.В. [и др.] // Экспозиция нефть газ. - 2013. - № 5. - С. 80-82.

20. Котельников, Л. В. Штуцерное дроссельно-регулирующее устройство / Котельников Л. В., Фоминых А. В. // Техническое обеспечение технологий производства сельскохозяйственной продукции. Материалы Всероссийской научно-практической конференции, 2017. - C. 10-13.

21. Сухов, С. А. Повышение эффрективности процесса регулирования потоков жидкости на основе совершенствования конструкции шиберных задвижек // Арматуростроение. - 2014. - № 1. С. $36-39$.

22. Chinyaev I.R., Fominykh A.V., Pochivalov E.A. The Method of Determining the Cavitation Characteristics of Valves // Procedia Engineering 150. 2016. - P. 260-265.

23. Определение пропускной характеристики задвижки шиберной запорно-регулирующей / Сухов С. А., Чиняев И. Р., Фоминых А. В. [и др.] // Экспозиция нефть газ. - 2015. - № 2. - С. $38-40$. 
24. Сухов, С. А., Фоминых, А. В. Пропускная характеристика задвижки шиберной // Нефтегазовый терминал выпуск 8: сборник научных статей Международной научнотехнической конференции «Транспорт и хранение углеводородного сырья»; под общ. ред. С. Ю. Подорожникова - Тюмень, ТюмГНГУ, 2015. - С. $202-207$.

25. Пошивалов, Е. А., Чиняев, И. Р., Фоминых А.В. и др. Анализ методик экспериментального определения кавитационных характеристик трубопроводной арматуры // Трубопроводная арматура. - 2016. - № 4 - С. 42-45.

26. Чиняев, И. Р., Фоминых, А. В., Ерошкин, В.С. Кавитация в шиберных задвижках // Территория «Нефтегаз». - 2013. - № 5. - С. 48-49.

27. Определение гидравлических и кавитационных характеристик клеточного клапана / Фоминых А.В., Пошивалов Е.А., Ильиных Е.А. [и др.] // Вестник Курганской ГСХА. - 2016. - № 1. C. $71-75$.

28. Опыт использования ГОСТ Р 55508-2013 при определении гидравлических и кавитационных характеристик запорно-регулирующего клапана клеточного / Чиняев И. Р., Пошивалов Е. А., Фоминых А.В. [и др.] // Территория «Нефтегаз». 2016. - № 7-8. - С. 96-100.

29. Задвижка запорно-регулирующая / Пошивалов Е.А., Сухов С.А., Фоминых А.В., Чиняев И.Р., Шанаурин А.Л. // Патент России на полезную модель №138816. 2014. Бюл. № 9.

30. Запорно-регулирующее устройство / Заславский Г.А., Рязанов В.А., Сухов С.А., Чиняев И.Р., Шанаурин А.Л., Фоминых А.В. // Патент России на полезную модель № 158069. 2015. Бюл. № 35.

31. Запорно-регулирующее устройство / Заславский Г.А., Рязанов В.А., Сухов С.А., Чиняев И.Р., Шанаурин А.Л., Фоминых А.В. // Патент России на изобретение № 2586958. 2016. Бюл. № 16.

32. Chinyaev I.R., Fominykh A.V., Sykhov S.A. Energy-Saving Shut-Off and Regulating Device // Procedia Engineering 150. - 2016. - P. 277-282.

33. ГОСТ Р 52720-2007 Арматура трубопроводная. Термины и определения. // М.: Стандартинформ, 2007. - 30 c.

34. Фоминых А.В., Чиняев И.Р., Шанаурин
А.Л., Ильиных Е.А. Трубопроводная арматура как основа систем пассивной защиты // Арматуростроение. - 2016. № 4 - С. 58-63.

35. Chinyaev I.R., Fominykh A.V., Ilinykh E.A. The valve is a shutoff for the passive protection systems of pipelines // Procedia Engineering 150. 2016. - P. 220-224.

36. Фоминых А.В., Овчинников Д.Н., Чиняев И.Р. Гидравлическая система удаления навоза из животноводческого помещения // Главный зоотехник. - 2013. - № 6. - С. 57-60.

37. Фоминых А.В., Шарипов А.Г., Овчинников Д.Н. Обеспечение устойчивой работы фильтрующих центрифруг. // ГУП «Куртамышская типография». - 2012. - С. 108.

38. Фоминых А.В., Шарипов А.Г. Обеспечение устойчивой работы фильтрующей центрифуги при производстве соевого молока // Интеграция науки и бизнеса в агропромышленном комплексе: материалы международной научно-практической конференции. - Курган: Изд-во Курганской ГСХА. 2014. - T. 3. - C. 111-116.

Дмитрий Владимирович Логинов, аспирант ФГБОУ ВО «Курганская государственная сельскохозяйственная академия им. T.C. Мальцева», email:krg.loginov@mail.ru, тел. +7909 17526 57.

Сухов Станислав Александрович, директор сборочного производства ООО НПФ «МКТ-АСДМ», e-mail:ooodok@bk.ru, тел. 8 (3522) 65-50-30.

Фоминых Александр Васильевич, доктор технических наук, профрессор, профрессор кафредры эксплуатации и ремонта машин, ФГБОУ ВО «Курганская государственная сельскохозяйственная академия имени Т.C. Мальцева», e-mail: prof_fav@mail.ru, тел.+791283902 53.

Чиняев Ильгиз Рашитович, кандидат технических наук, директор НПФ «МКТ-АСДМ». e-mail: ruk_mkt@mail.ru, тел. 8 (3522) 65-50-30. 